SVU- International Journal of Veterinary Sciences, 3 (1): 123-132, 2020.

Print ISSN: 2535-1826

\title{
Effect of zinc oxide nanoparticles on anxiety-related behaviors in male rats
}

\section{Ahmed A. Mohammed ${ }^{1 *}$, Hayam Hamdy ${ }^{2}$, Ghada Abd El-Reda ${ }^{3}$, Mahmoud Soliman ${ }^{4}$, Usama. T. Mahmoud ${ }^{1}$}

${ }^{1}$ Department of Animal and poultry behavior and management, Faculty of Veterinary Medicine, Assiut University, 71526, Egypt. ${ }^{2}$ Department of Forensic Medicine, Faculty of Veterinary Medicine, New Valley University, 72511, Egypt. ${ }^{3}$ Physics Department, Faculty of Science, Assiut University, 71515, Egypt. ${ }^{4}$ Department of Pathology and Clinical Pathology, Faculty of Veterinary Medicine, Assiut University, 71526, Egypt.

\section{Abstract}

The objective of this study was to investigate the influences of zinc oxide nanoparticles (ZONPs) on the anxiety-related behaviors of male albino rats. Because of the sexual differences found in the anxiety related disorders, thirty-six male albino rats 40-days old weighed from 130 to $150 \mathrm{~g}$ and divided into three groups; group I served as a control, groups II and III were subjected to daily intraperitoneal injection of ZONPs $(30 \mathrm{mg} / \mathrm{kg}$ or $60 \mathrm{mg} / \mathrm{kg}$, respectively) for 5 days sequentially. Each treatment contained four replicates of 3 rats each. Eight rats per treatment (i.e.2 rats/replicate) were randomly taken and marked with green livestock spray for behavioral observation and anxiety testing on same day of injection. Elevated plus maize, open field, forced swimming, tail suspension tests were used for anxiety testing. Afterwards, the rats were sacrificed, and the histopathological evaluation of brain tissue was done. The results showed that the intraperitoneal injection of ZONPs reduced the standing behavior, climbing time of the forced swimming test, and increased the sleeping behavior, immobility time of the forced swimming test and agitation and immobility time of the tail suspension test $(\mathrm{P}<0.05)$; while the ZONPs had no effects on alert activities, open field test, and elevated plus maize test $(\mathrm{P}>0.05)$ in ZONPs injected groups. In addition, ZONPs induced necrosis of the nerve cells in cerebral cortex and the Purkinje cells in cerebellum.

Keywords: Rats, Anxiety, Zinc oxide, Behavior, Brain.

DOI: $10.21608 / \mathrm{svu} .2020 .22360 .1041$

Received: January 13, 2020

*Corresponding Author: Ahmed A. Mohammed. $\quad$ E-mail: Ahmed.abd_elhafez@vet.au.edu.eg

Citation: Mahmoud et al., 2020, Effect of zinc oxide nanoparticles on anxiety-related behaviors in male rats.

SVU-IJVS 2020, 3(1): 123-132.

Copyright: (C) Mahmoud. This is an open access article distributed under the terms of the creative common attribution license, which permits unrestricted use, distribution and reproduction in any medium provided the original author and source are created.

Competing interest: The authors have declared that no competing interest exists.

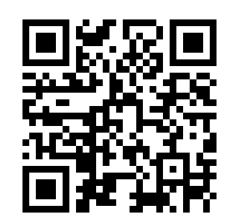




\section{Introduction}

Nanotechnology creates and manufactures many types of engineered nanoparticles with size of up to $100 \mathrm{~nm}$ (Nanotechnology Research Directions, 1999). The small particle size of Zinc oxide nanoparticles (ZONPs) increases the surface area per unit mass and enhances the reactivity of them in a cell at very low concentration because of their special chemical and physical features and their elevated surface area to volume ratio (Drexler et al., 1987), so they are also being explored for their potential use in agriculture, material science, diagnostic and medical applications, food industry, and cosmetic (Siddiqi et al., 2018). ZONPs are being used in the food manufacture as additives and packaging due to their antimicrobial characteristics (Donaldson et al., 2005). Special interest being paid to their potential toxicity, including cytotoxic, proinflammatory and genotoxic effects due to increased use of ZONPs and exposure to these nanoparticles has been spreading out. ZONPs can enter the body through many ways such as injection, inhalation, and ingestion, they may then move to blood stream leading to harmful physiological effects.

Some reports consider that ZONPs as a substance of low toxic effect, due to presence of it in the human system as an essential trace element and its importance in the activity of many enzymes like alcohol dehydrogenase, carboxypeptidase, and carbonic anhydrase (Osmond and McCall, 2010; Zhao and Castranova, 2011). It is considered as an essential component or added as a nutritional supplement of many foods, so during evaluation of toxicity of nanoparticles in organs, zinc attracts little attention, however, many articles have revealed that increasing the dose of ZONPs can induce apoptosis in murine liver cells and enhance severe oxidative stress
(Sharma et al., 2012). Moreover, recent reports have revealed that ZONPs are toxic to rodents and animals, and they returned the ZONPs toxicity to the synthesis of metallic cations $\mathrm{Zn}^{2+}$ are the main causes of toxicity (Pujalté et al., 2011). Previous researches reported that some organ may show inflammation, oxidative stress and heart problems. Campbell et al., (2005) reported that ZONPs might mitigate cognitive impairment and abnormal behaviors in mice like anxiety-like behaviors, probably via modulation neuronal synaptic functions and plasticity (Xie et al., 2012). Moreover, ZONPs may organize ionic homeostasis and the biological functions of neurons and have great effect in central nervous system, which shed light on the possible application and treatment in neurotransmitter system disorders (Zhao et al., 2009).

Differences in dosage or ZONPs may be responsible for these conflicting results. Therefore, the objective of the study was to observe the influence of two dosages of ZONPs injected intraperitonially on anxiety related behavior and brain histopathology in rat model. We hypothesized that intraperitoneal injection of high doses ZONPs would have a harmful effect on anxiety related

\section{MATERIALS AND METHODS}

\section{Zinc oxide nanoparticles (ZONPs) preparation}

ZONPs were synthesized using procedures published by Othman et al., (2017). Scanning electron microscopy (SEM) image of synthesized ZONPs was captured in The Electron Microscopy (EM) unit at Assiut University (Figure, 1). ZONPs suspension was performed using physiological saline solution. We dispersed ZONPs in the physiological saline solution (sterile and fresh), and ultrasonic liquid processor: Sonicator 4000 was used for 20 
min to dissolve the suspension completely; ZONPs suspension was vortexed for $1 \mathrm{~min}$ before the intraperitoneal injections.

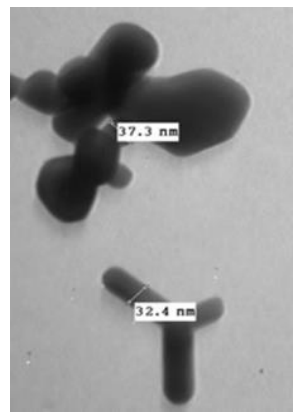

Fig. (1) Scanning electron microscopy (SEM) image of synthesized ZONPs.

\section{Animals and housing}

Thirty-six male albino rats 40-days old, weighing 130-150 gm at the beginning of the experiment and divided in to 3 groups with 4 replicates ( 3 rats per cage) (at $25^{\circ} \mathrm{C}$, with free access to food and water under a 10:14 dark/ light cycle). Group I (control) injected with physiological saline solution, group II received ZONPs at dose of $30 \mathrm{mg} /$ $\mathrm{kg}$ body weight, and group III received ZONPs at dose of $60 \mathrm{mg} / \mathrm{kg}$ body weight, through intraperitoneal injection for 5 days sequentially. Male albino rats were used in this experiment because of the sexual differences found in general anxiety disorders, many studies have also cleared that females are more likely to suffer from social anxiety disorders than males (Kessler et al, 1994; Schneier et al, 1992). Besides, observation of rat behavior revealed that aggression between dominant and subordinate males was negligible (van Zegeren, 1980). Further, it has long been known that, especially in animal ethology and neuroscience, using of rats have a number of advantages, such as the relatively large size of their brains, which makes brain surgery much easier, they are also much easier to handle than mice and less easily stressed by human contact (Meijer et al., 2007).

\section{Behavioral observations}

Twelve rats per treatment from four independent cages ( 3 rats per cage) were randomly taken and marked with green livestock spray for behavioral observation and anxiety testing. Observation of the rats' behaviors was done once a day from 10:00 to $12: 00$ am for 5 consecutive days, after injection of ZONPs in the same days of injection according to previously mentioned ethogram (Table 1) using instantaneous scan direct observation method (Altmann, 1974). The rats' behavioral patterns were recorded from outside of the cages with $1 \mathrm{~m}$. The persons who conducted the behavioral observation were trained and they were blind to the treatments. Behavioral patterns of all rats per cage were scored 12 times per observation session (Mohammed et al., 2018).

Table (1) Behavioral ethogram.

\begin{tabular}{|c|l|}
\hline Behavior & \multicolumn{1}{|c|}{ Definition } \\
\hline Sleep & $\begin{array}{l}\text { The rat is motionless, } \\
\text { either lying curled on its } \\
\text { side, or sitting curled up, } \\
\text { with its head tucked into } \\
\text { the body. }\end{array}$ \\
\hline Stand & $\begin{array}{l}\text { The rat stands only on its } \\
\text { leg. }\end{array}$ \\
\hline Alert & $\begin{array}{l}\text { The rat is sitting curled } \\
\text { up, but the face is lifted, } \\
\text { the rat either sits } \\
\text { motionless, or appears to } \\
\text { direct its head towards } \\
\text { sounds outside the cage. }\end{array}$ \\
\hline
\end{tabular}

\section{Behavioral tests}

Eight rats per treatment from four independent cages ( 2 rats per cage) were used in some behavioral tests to evaluate the anxiety-related behaviors (Figure, 2). 


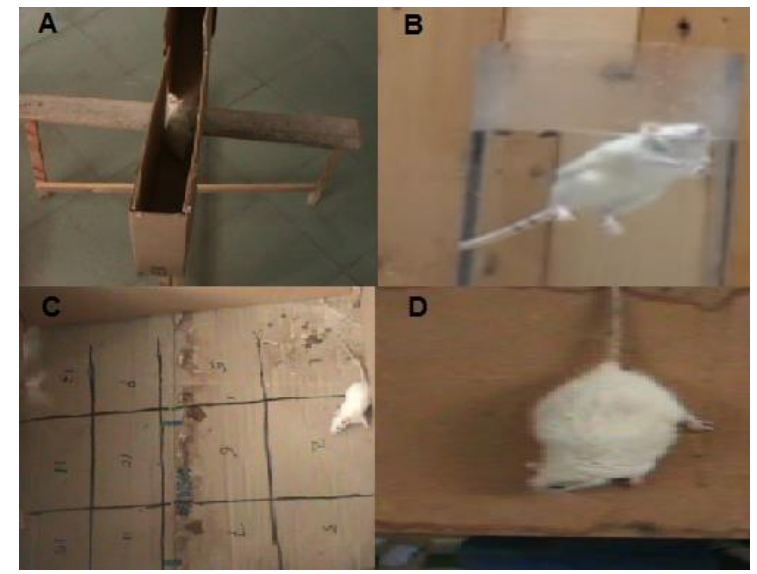

Fig. (3) Behavioral tests in the controls and ZONPs injected rats. (A) Elevated plus maiz test. (B) Forced swimming test. (C) Open field test. (D) Tail suspension test.

\section{Elevated plus maze test}

Anxiety-related behaviors were assessed by using the elevated plus maze according to (Maaroui et al., 2009). The device was designed of yellowish wood. We elevated the device at height of $70 \mathrm{~cm}$ and the arms were $60 \mathrm{~cm}$ in long and $10 \mathrm{~cm}$ in width. We closed the close arms by 50 $\mathrm{cm}$ edges and left the open edges of the open arms to allow the rats to enter (Treit et al., 1993). We performed the test by putting the tested rats in the center of the device for 5 min. we recorded the time spent by the tested rats in the different arms of the device, in the same time, we calculated the number of enters in the different parts of the device. We used the alcohol to clean the device between the tested rats to eliminate the odor of the previous rat.

\section{Tail suspension test}

We used the tail suspension test accordingly to previously reported methodologies (Shinde et al., 2015). The tested rats were isolated and suspended 60 $\mathrm{cm}$ from the ground and fixed by adhesive tap $1 \mathrm{~cm}$ from the base of the tail for $5 \mathrm{~min}$, we placed a thin wooden square under the forepaws of the tested rat to decrease the weight on the tail by placing the forepaws on it. We recorded the immobility and agitation times. The immobility was defined as the disappearance of the movement of the rat, while the agitation was defined as struggling of the forepaws against the wooden square.

\section{Open field test}

Anxiety-related behavioral patterns (locomotion in the peripheral and central circle of the device, and the rearing) were investigated in the open field test according to (Ben-Slama et al., 2015). Rats in the control and ZONPs-treated groups were tested at the end of the experiment. The devise was a wooden yellow circular enclosure $(70 \mathrm{~cm}$ in high and $110 \mathrm{~cm}$ diameter). We divided the device in to central and peripheral circle; the central circle was divided in to 6 divisions of equal size. At the beginning of the behavioral test, the tested rats were put in the peripheral circle of the device. We cleaned the device using alcohol solution between the rats to eliminate the odors of the previous one.

\section{Forced swimming test}

We used the force swimming test to evaluate the anxiety-related behaviors accordingly to previously reported methodologies (Guzzetti et al., 2008). The test was performed by using a tank containing clean water (diameter $10 \mathrm{~cm}$, height $15 \mathrm{~cm}$ ). We put the tested rats individually in the tank for $5 \mathrm{~min}$ at the end of the experiment between 2:00 and 4:00 p.m. we placed a digital camera above the tank to record the behavioral patterns (immobility number, immobility time and climbing time). Before returning the tested rat to its home cage at the end of the test, we dried it by using a clean towel. Immobility was defined as the disappearance of the 
movement of the rat, floating without any movement and stopping of the struggling behavior. Swimming was defined as the movement of the forepaws of the rat. Climbing was defined as the struggling of the forepaws of the rat against the walls of the tank.

\section{Histopathological examination}

At the end of the experiment, the rats were anesthetized by inhalation of overdose of pentobarbital followed by rapid cervical dislocation. This was followed by harvesting of brain tissues, which were placed in $10 \%$ formaldehyde. and brain specimens were cut and fixed in a10\% neutral buffered formalin. The formalinfixed samples were routinely processed, embedded in paraffin, and sectioned. Serial $5 \mu \mathrm{m}$ sections were stained with Mayer's hematoxylin (Merck, Darmstadt, Germany) and eosin (Sigma, Missouri, USA). Afterwards, slides were examined microscopically, and the histological evaluation was performed in a blind fashion on coded samples, and a comparison was made with the sections from the control group.

\section{Statistical Analysis}

The experimental design was conducted in a randomized block design. Pen was considered the experimental unit. Means of the data were analyzed by using the GLM procedure in JMP (SAS Institute, Cary, NC). The normality of the data was analyzed by the Shapiro-Wilk test. The overall effects of the ZONPs injection were analyzed statistically by one-way analysis of variance (ANOVA). Means were compared by Tukey- Kramer test when a significant difference was detected. Expression of the findings was designed as the mean \pm SE. Statistical significance was declared when the coefficients were at a probability of $\alpha$ less than 0.05 .

\section{Results}

\section{Behavioral patterns}

The ZONPs effects on behavioral activities are presented in in Table 2 . ZONPs injection increased $(\mathrm{P}<0.05)$ rats' sleeping. Compared with control. Both doses of ZONPs increased the sleeping of rats. However, standing frequently was reduced. Moreover, there were no significant differences in alert behavior between the control and ZONPs injected groups $(\mathrm{P}>0.05)$.

Table (2) Effect of ZONPs injection on some behavioral patterns in rats.

\begin{tabular}{|l|l|l|l|}
\hline Treatment $^{\text {I }}$ & \multicolumn{3}{|c|}{ Behavioral pattern } \\
\hline & Sleeping\% & Standing\% & Alert\% \\
\hline Group I & $18 \pm 11^{\mathrm{b}}$ & $65 \pm 90^{\mathrm{a}}$ & $59 \pm 29$ \\
\hline Group II & $74 \pm 11^{\mathrm{a}}$ & $12 \pm 30^{\mathrm{b}}$ & $26 \pm 70$ \\
\hline Group III & $52 \pm 14^{\mathrm{ab}}$ & $14 \pm 11^{\mathrm{b}}$ & $23 \pm 10$ \\
\hline P value & 0.046 & 0.007 & 0.070 \\
\hline
\end{tabular}

${ }^{\mathrm{a}, \mathrm{b}}$ Means \pm SE with different superscripts in the same row differ significantly $(\mathrm{P}<0.05)$.

${ }^{1}$ Treatments were divided into three groups; group I served as a control, groups II and III were subjected to daily intraperitoneal injection of ZONPs for 5 days sequentially. Each treatment contained four replicates of 3 rats each.

\section{Behavioral tests}

\section{Elevated plus maze test}

The ZONPs injection effects on elevated plus maiz test parameters, time spent in open arms, number of enters in open arms, time spent in closed arms and number of enters in closed arms were presented in Table 3. There were no significant differences in all parameters of elevated plus maiz test between the control and ZONPs injected groups $(\mathrm{P}>0.05)$. 
Table (3) Effect of ZONPs injection on parameters of elevated plus maize test in rats.

\begin{tabular}{|l|l|l|l|l|}
\hline \multicolumn{5}{|c|}{ Elevated plus maize test } \\
\hline & $\begin{array}{l}\text { Time spent in } \\
\text { open arms(min) }\end{array}$ & $\begin{array}{l}\text { Number of enters } \\
\text { in open arms(min) }\end{array}$ & $\begin{array}{l}\text { Time spent in } \\
\text { closed arms (min) }\end{array}$ & $\begin{array}{l}\text { Number of enters } \\
\text { in closed arms } \\
\text { (min) }\end{array}$ \\
\hline Group I & $0.86 \pm 0.44$ & $0.10 \pm 0.10$ & $2.05 \pm 0.20$ & $0.25 \pm 0.14$ \\
\hline Group II & --- & --- & $2.19 \pm 0.22$ & $0.39 \pm 0.22$ \\
\hline Group III & --- & --- & $2.47 \pm 0.01$ & $0.11 \pm 0.11$ \\
\hline P value & 0.084 & 0.422 & 0.292 & 0.250 \\
\hline \hline
\end{tabular}

${ }^{\mathrm{a}, \mathrm{b}}$ Means $\pm \mathrm{SE}$ with different superscripts in the same row differ significantly $(\mathrm{P}<0.05)$.

${ }^{1}$ Treatments were divided into three groups; group I served as a control, groups II and III were subjected to daily intraperitoneal injection of ZONPs for 5 days sequentially. Each treatment contained four replicates of 3 rats each.--- means no rat entered these arms.

\section{Tail suspension test}

The ZONPs injection effects on tail suspension test parameters, immobility time, and agitation time were presented in Table 4. ZONPs injection significantly ( $\mathrm{P}<$ $0.05)$ increased rats' immobility and agitation time in group III in comparison to the control.

Table (4) Effect of ZONPs injection on parameters of tail suspension test in rats.

\begin{tabular}{|l|l|l|}
\hline \multicolumn{3}{|c|}{ Tail suspension test } \\
\hline & Immobility time & Agitation time \\
\hline Group I & $1.83 \pm 0.07^{\mathrm{b}}$ & $1.47 \pm 0.05^{\mathrm{b}}$ \\
\hline Group II & $1.96 \pm 0.02^{\mathrm{ab}}$ & $1.67 \pm 0.11^{\mathrm{ab}}$ \\
\hline Group III & $2.05 \pm 0.003^{\mathrm{a}}$ & $2.08 \pm 0.11^{\mathrm{a}}$ \\
\hline P value & 0.032 & 0.012 \\
\hline
\end{tabular}

${ }^{\mathrm{a}, \mathrm{b}}$ Means $\pm \mathrm{SE}$ with different superscripts in the same row differ significantly $(\mathrm{P}<0.05) .{ }^{1}$ Treatments were divided into three groups; group I served as a control, groups II and III were subjected to daily intraperitoneal injection of ZONPs for 5 days sequentially. Each treatment contained four replicates of 3 rats each

\section{Open field test}

The means of the open field test parameters, rearing, locomotor activity in line crossing, locomotor activity in line central were presented in Table 5. The differences in rearing, locomotor activity in line crossing, and locomotor activity in line central were disappeared $(\mathrm{P}>0.05)$.

Table (5) Effect of ZONPs injection on parameters of open field test in rats.

\begin{tabular}{|l|l|l|l|}
\hline \multicolumn{3}{|c|}{ Open field test } \\
\hline & Rearing(no.) & $\begin{array}{l}\text { Locomotor activity } \\
\text { in line crossing } \\
(\mathrm{n} 0 .)\end{array}$ & $\begin{array}{l}\text { Locomotor activity } \\
\text { in line central (no.) }\end{array}$ \\
\hline Group I & $1.50 \pm 0.29$ & $20 \pm 2.89$ & $0.00 \pm 0.00$ \\
\hline Group II & $0.50 \pm 0.29$ & $21 \pm 9.24$ & $6.50 \pm 3.17$ \\
\hline Group III & $1.00 \pm 0.58$ & $5 \pm 2.89$ & $0.00 \pm 0.00$ \\
\hline P value & 0.30 & 0.175 & 0.073 \\
\hline
\end{tabular}

\footnotetext{
${ }^{\mathrm{a}, \mathrm{b}}$ Means \pm SE with different superscripts in the same row differ significantly $(\mathrm{P}<0.05)$.
}

${ }^{1}$ Treatments were divided into three groups; group I served as a control, groups II and III were subjected to daily intraperitoneal injection of ZONPs for 5 days sequentially. Each treatment contained four replicates of 3 rats each.

\section{Forced swimming test}

The ZONPs injection effects on forced swimming test parameters, immobility time, immobility number, and climbing time were presented in Table 6 . ZONPs injection significantly $(\mathrm{P}<0.05)$ increased rats' immobility number and decreased the climbing time in group III in comparison to the control. However, there were no significant differences in immobility time between the control and ZONPs injected groups $(\mathrm{P}>0.05)$. 
Table (6) Effect of ZONPs injection on parameters of forced swimming test in rats.

\begin{tabular}{|l|l|l|l||}
\hline \multicolumn{4}{|c|}{ Forced swimming test } \\
\hline & Immobility time & $\begin{array}{l}\text { Immobility } \\
\text { Number }\end{array}$ & Climbing time \\
\hline Group I & $1.48 \pm 0.21$ & $1.13 \pm 0.03^{\mathrm{b}}$ & $1.40 \pm 0.12^{\mathrm{a}}$ \\
\hline Group II & $1.51 \pm 0.01$ & $1.19 \pm 0.01^{\mathrm{b}}$ & $1.28 \pm 0.05^{\mathrm{ab}}$ \\
\hline Group III & $1.53 \pm 0.06$ & $1.34 \pm 0.2^{\mathrm{a}}$ & $1.06 \pm 0.03^{\mathrm{b}}$ \\
\hline P value & 0.964 & 0.001 & 0.053 \\
\hline
\end{tabular}

${ }^{\mathrm{a}, \mathrm{b}}$ Means $\pm \mathrm{SE}$ with different superscripts in the same row differ significantly $(\mathrm{P}<0.05)$.

${ }^{1}$ Treatments were divided into three groups; group I served as a control, groups II and III were subjected to daily intraperitoneal injection of ZONPs for 5 days sequentially. Each treatment contained four replicates of 3 rats each.

\section{Histopathological findings}

The brain sections of the controltreated rats showed normal cellularity with healthy neurons and prominent nuclei of the cerebral cortex (Fig. $3 \mathrm{~A}$ and B) as well as normal layers of the cerebellar cortex (Fig. $3 \mathrm{C}$ and $\mathrm{D}$ ). The neuropathological lesions observed in rats treated with $30 \mathrm{mg} / \mathrm{kg}$ or 60 $\mathrm{mg} / \mathrm{kg}$ ZONPs were neuronal necrosis in the cerebral cortex (Fig. $3 \mathrm{E}, \mathrm{F}, \mathrm{I}$, and J). The necrotic neurons were red, angular, and shrunken and their nuclei were contracted and dense. In addition, necrosis of the Purkinje cells in the cerebellum were necrotic with shrunken cell bodies and condensed nuclei (Fig. 3 G, H, K, and L), which were prominent in rats treated with $60 \mathrm{mg} / \mathrm{kg}$ ZONPs.

\section{Discussion}

Nowadays, ZONPs could be dangerous due to toxicological and pathological effects. ZONPs retention in food and environment is common and exposure to them continuously may affect animal and human health (Bia et al., 2017).
Many researchers have revealed that ZONPs are toxic through different routes like oral or intraperitoneal injection (Dhawan et al., 2010). Plus, maize, open field test, tail suspension test and forced swim test are usually adopted to detect and evaluate depressive-like behaviors (Battegay et al., 1998). Here, our findings exhibited that ZONPs increased sleeping and decreased standing behaviors and increased the immobility and agitation of forced swimming and tail suspension tests, however, it decreased the climbing time of the forced swimming test.

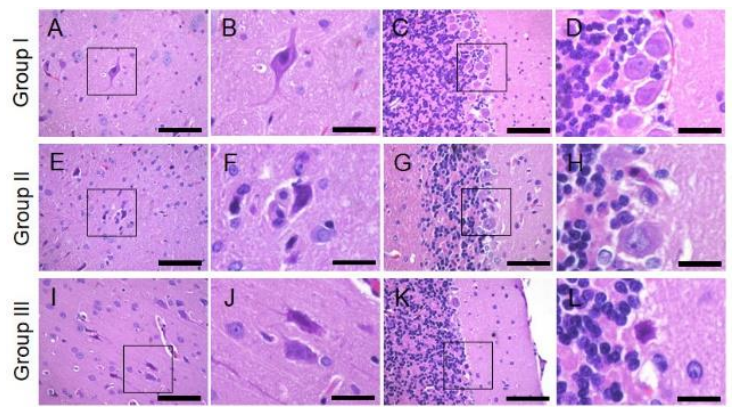

Fig. (3) Histopathological changes in the brain of control- and ZONPs -treated rats. (A-D) Brain sampled from control-treated group (group I) showed normal cellularity and nerve cells of the cerebral cortex (A and B) and normal layers of the cerebellum (C and D). (E-L) Brain sections from rats treated with $30 \mathrm{mg} / \mathrm{kg}$ (group II) (E-H) or $60 \mathrm{mg} / \mathrm{kg}$ (group III) (I-L) showed red and shrunken neurons with condensed nuclei indicating necrosis of the nerve cells in the cerebral cortex (E, F, I, and J) and Purkinje cells in the cerebellum ( $\mathrm{G}, \mathrm{H}, \mathrm{K}$, and $\mathrm{L}$ ). Bars A, C, E, G, I, and K =200 $\mu \mathrm{m}$. Bars B, D, F, H, $\mathrm{J}$, and $\mathrm{L}=50 \mu \mathrm{m}$. Using of different bars to make the histopathological changes clearer.

In the current experiment, the results showed significant increase in the sleeping and decrease in standing. These behavioral changes may be related to depression when rats happened to be susceptible to despair and hopeless.

Our findings have shown that, intraperitoneal injection of ZONPs has no significant effect on the activity of rats measured in the open field and plus maze 
tests such as locomotion, exploratory, and anxiety-like behaviors. These findings were supported by Amara et al. (2014) who revealed that, the absence of correlation between ZONPs accumulation in brain following ZONPs treatment and behavioral patterns of rats.

On the contrary, ZONPs treatment increased the immobility and agitation of forced swimming and tail suspension tests; however, it decreased the climbing time of the forced swimming test. Function of memory and cognition was conducted through the hippocampus, referring to the synaptic functions and neuron network, depending on the synaptic transmission characteristics and functions(Adolphs et al., 2005; Addis et al., 2007; Buckner and Carroll, 2007). Furthermore, ZONPs treatment induced neuronal necrosis in the cerebrum and cerebellum. Changes in the locomotion, memory, and anxiety-like behaviors, and emotion may indicate the depression and impairment of learning acquisition effectively. These behavioral and emotional changes could be attributed to necrosis of the brain cell (Min et al., 2009).

\section{Conclusion}

In the current study, the results indicated that ZONPs increased sleeping and decreased standing behaviors and increased the immobility and agitation of forced swimming and tail suspension tests. The current results supported that ZONPs may induce behavioral and emotional changes in rat model. However, further studies should be conducted to examine the mechanisms by which the ZONPs induce necrosis of brain cell.

\section{Conflict of interest}

We do not have conflicts of interest to disclose.

\section{Acknowledgements}

Thanks for all the scientists, staff and all of the graduate students at animal and poultry behavior and management department, Faculty of Veterinary Medicine, Assiut University who contributed significantly throughout the development and sample collection of the study. Special thanks to vet. Ahmed Aboharon, demonstrator of animal and poultry behavior and management, faculty of veterinary medicine, Assiut University, for his productive contribution in the behavioral observation.

\section{References}

Addis DR, Schacter DL (2008). Constructive episodic simulation: temporal distance and detail of past and future events modulate hippocampal engagement. Hippocampus 18, 227237.

Adolphs R, Tranel D, Buchanan TW (2005). Amygdala damage impairs emotional memory for gist but not details of complex stimuli. Nat. Neurosci. 8: 512-518.

Altmann J (1974). Observational study of behavior. Sampl. Methods Behav. 49: 227-266.

Amara S, Ben-Slama I, Mrad I, Rihane N, Jeljeli M (2014). Acute exposure to zinc oxide nanoparticles does not affect the cognitive capacity and neurotransmitters levels in adult rats. Nanotoxicology. Suppl. 1: 208-215.

Battegay R (1998). Depression as a psychophysical illness phenomenon. Praxis (Bern 1994); 87: 263-70.

Ben-Slama I, Mrad I, Rihane N, Mir LE, Sakly M (2015). Sub-Acute Oral Toxicity of Zinc Oxide Nanoparticles in Male Rats. J. Nanomed. Nanotechnol. 6: 284. 
Bai DP, Zhang XF, Zhang GL, Huang YF, Gurunathan S (2017). Zinc oxide nanoparticles induce apoptosis and autophagy in human ovarian cancer cells. Int. J. Nanomed. 12: 6521.

Buckner RL, Carroll DC (2007). Selfprojection and the brain. Trends Cogn. Sci. 11, 49-57.

Campbell A, Oldham M, Becaria A, Bondy SC, Meacher (2005). Particulate matter in polluted air may increase biomarkers of inlammation in mouse brain. Neurotoxicology. 26: 133-140.

Dhawan A Sharma V (2010). Toxicity assessment of nanomaterials: methods and challenges. Anal. Bioanal. Chem. 398: 589-605.

Donaldson K, Tran L, Jimenez LA, Dufin R, Newby DE (2005). Combustionderived nanoparticles: a review of their toxicology following inhalation exposure. Part.Fibre. Toxicol. 2: 10.

Drexler, KE (1987). Engines of Creation The Coming Era of Nanotechnology," Anchor, Reprint edition, New York, 1987.

Guzzetti S (2008). Strain differences in paroxetine-induced reduction of immobility time in the forced swimming test in mice: Role of serotonin. Eur. J. Pharmacol. 594: 117-124.

Kessler RC, McGonagle KA, Zhao S, Nelson CB, Hughes M, Eshleman $S$ (1994). Lifetime and 12-month prevalence of DSM-III-R psychiatric disorders in the United States. Results from the National Comorbidity Survey. Arch Gen Psychiatry 51: 819.

Maaroui K, Ammari M, Jeljeli M, Roy V, Sakly (2009). Impairment of emotional behavior and spatial learning in adult Wistar rats by ferrous sulfate. Physiol. Behav. 96: 343-349.
Meijer M. K., Sommer R., Spruijt B. M., van Zutphen L. F. M. Baumans V. (2007). Influence of environmental enrichment and handling on the acute stress response in individually housed mice. Lab. Anim. 41, 161-173.

Min SS, Quan HY, Ma J, Han JS, Jeon BH, Seol GH (2009). Chronic brain inflammation impairs two forms of long-term potentiation in the rat hippocampal CA1 area. Neurosci. Lett. 456: 20-4.

Mohammed AA, Jacobs JA, Murugesan GR, Cheng HW (2018). Effect of dietary synbiotic supplement on behavioral patterns and growth performance of broiler chickens reared under heat stress. Poult. Sci. 0: $1-8$.

Nanotechnology Research Directions: IWGN Workshop Report - Vision for Nanotechnology R\&D in the Next Decade," WTEC, Loyola College in Maryland, M. C. Roco, S. Williams, and P. Alivisatos, Eds., September 1999; "National Nanotechnology Initiative: Leading to the Next Industrial Revolution," A Report by the Interagency Working Group on Nanoscience, Engineering and Technology Committee on Technology, National Science and Technology Council, Washington, DC, February 2000.

Othman AA, Osman MA, Ibrahim EMM, Ali M.A (2017). Sonochemically Synthesized $\mathrm{ZnO}$ Nanosheets and Nanorods: Annealing Temperature Effects on the Structure, and Optical

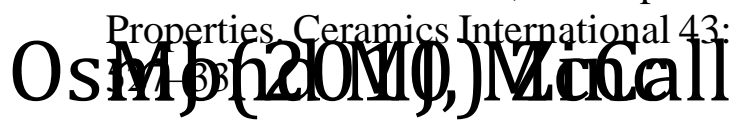

Osmond MJ, McCall MJ (2010). Zinc oxide nanoparticles inmodern sunscreens: an analysis of potential exposure andhazard. Nanotoxicology. 4:15-41. 
Pujalté I, Passagne I, Brouillaud B, Tréguer M, Durand E (2011). Cytotoxicity and oxidative stress induced by different metallic nanoparticles on human kidney cells. Part.Fibre. Toxicol 8: 10-11.

Schneier FR, Johnson J, Hornig CD, Liebowitz MR, Weissman MM (1992). Social phobia. Comorbidity and morbidity in an epidemiologic sample. Arch Gen Psychiatry 49: 282-288.

Sharma V, Singh P, Pandey AK, Dhawan A (2012). Induction of oxidative stress, DNA damage and apoptosis in mouse liver after sub-acute oral exposure to zinc oxide nanoparticles. Mutat. Res. 745: 84-91.

Shinde V, Yegnanarayan R, Shah P, Gupta A, Pophale P (2015). Antidepressantlike activity of flunarizine in modified tail suspension test in rats. North. Am. J Med. Sci. 7:100-103.

Siddiqi KS, Husen A, Rao RAK (2018). A review on biosynthesis of silver nanoparticles and their biocidal properties. J Nanobiotechnol. 16:14.
Treit D, Menard J, Royan C (1993). Anxiogenic stimuli in the elevated plus-maze. Pharmacol. Biochem. Behav. 44: 463-469.

van Zegeren K. (1980). Variations in aggressiveness and the regulation of numbers in house mouse populations. Neth. J. Zool. 30, 635770.

Xie Y, Wang Y, Zhang T, Ren G, Yang Z (2012). Effects of nanoparticle zinc oxide on spatial cognition and synaptic plasticity in mice with depressive-like behaviors. J Biomed. Sci. 19: 14.16

Zhao J, Xu L, Zhang T, Ren G, Yang Z (2009). Influences of nanoparticle zinc oxide on acutely isolated rat hippocampal CA3 pyramidal neurons. Neurotoxicology. 30: 220230.

Zhao J, Castranova V (2011). Toxicology of nanomaterials usedin nanomedicine. J Toxicol Environ Health B. 14:593-632. 